\title{
Design and Status of the Dipole Spectrometer Magnet for the ALICE Experiment
}

\author{
D. Swoboda, CERN ${ }^{(1)}$, V. Bartenev, JINR ${ }^{(2)}$, I. Bogouslavski, JINR ${ }^{(2)}$, V. Datskov, JINR ${ }^{(2)}$, \\ E. Koshurnikov, Neva Magnetsi ${ }^{(3)}$, A. Shabujov, JINR ${ }^{(2)}$, Y. Shishov, JINR ${ }^{(2)}$, A. Vodopianov, ,IINR ${ }^{(2)}$
}

A large Dipole Magnet is required for the Mton Arm spectrometer of the $\triangle \mathrm{LICF}$ experiment in the future $\mathrm{LHC}$.

The absence of constraints of symmetry and homogeneity of the magnetic fickd has lead to a design dominated by economical and feasibility considerations.

In March 1997 the decision was taken to build a resistive dipole magnet for the muon spectrometer ol the ALICE experiment. Since then design work has been pursued in JINR/Russial and at CRRN. While a common eoneept las been adopted for the construction of the sted care, two different proposals bave been made for the manufacturing technology of the excitation coils. In both eases, however, the conductor material will be Almminum. The general concept of the dipole magnet is based on a window frame return yoke, falbricated from low carbon stecl slicuts. The flat vertical poles follow the defined acceptance angle of 9 degrec. The excitntion eoils are of saddle type. The coils are wound from large hollow Aluminum profiles. They are cooled by pressurized demineralized water. 'The coil ends are located to both sides of the magnet yoke and determine the overall length of the magnet. The main thex direction in the gap is horizontal and perpendicular to the LHC besam axis.

both coil concepts and the underlying manufacturing technology are compared and the present stutus of the development of the magnet is described.

\section{INTROUUCTION}

The dipole magnet is a major part of the ALICE muon spectrometer and provides the bending power to measure the momenta of muons. The aperture and lield integtal ate determined by the requirements on mass resolution and angular aceptance.

Different proposals for the muon magnel have been evaluated. The AJICE Collaboration chose it resistive dipole magnet at the meeting in Match 1997 and a Preliminary Design Report [1] for the magnet was presented in March 1998.

The magnet will be placed dircetly adjacent to the $\mathrm{I} 3$ solenoid magnel, which is already installed and used at present for one of the LEP experiments. The dipole will be installed on a movable platfotm is order to be rolled back to allow intervention on the muon firont absorber.

In addition, the magnet will serve als a support for the muon absorber and beam shielding.

Manuscript ruceived Soptember 25, 1999

(1) CIRRN, Geneva, CII

(2) JINR, Dubne, RU

(3) Neva Magnets, St Petersburg, RU
The magnet will be powered by a de power supply. The coil will be water-cooled with demineralized water.

The concept of the magnet is based on a window fiame return yoke that is fabricated from low carbon steel sheets. The general layout of the magnel is shown in Fig. 1. The main parameters for the version with contintously wound coils are given in Table 1.

Table 1. Main Characteristics of the Magnel

\begin{tabular}{|c|c|c|}
\hline Parameter & Valuc & Unit \\
\hline Max Flux density & 0.67 & $\mathrm{I}^{1}$ \\
\hline Bchding Slrength & 3.00 & $\operatorname{Tm}$ \\
\hline Avg. Gal] widih & 3,30 & m \\
\hline Amperetultos & 1.85 & $\mathrm{MA}$ \\
\hline Operating Curtent & 6.42 & $\mathrm{kA}$ \\
\hline Coil Voltage & 572 & $\mathrm{~V}$ \\
\hline Power & 3.67 & MW \\
\hline Inductance & 0.70 & $\mathrm{H}$ \\
\hline Diff. Pressure & 14.3 & bat \\
\hline Difi. Temperature & 30 & ${ }^{\circ} \mathrm{C}$ \\
\hline Tolal woight & 835 & Ionnes \\
\hline $\begin{array}{l}\text { Overall Dimensions } \\
(\mathrm{H} \times \mathrm{W} \times \mathrm{C})\end{array}$ & $8.6 \times 6.6 \times 5.0$ & $m \times m \times m$ \\
\hline
\end{tabular}

The flat vertical poles follow the required acceptance angle of 9 degrees. The excitation coils are of saddle type. "I"wo concepts for a conventional coil, have been proposed [2] [3]. In both cases they are wound from hollow aluminum conductor of large cross-section. The coil ends arc located to buth sides of the maghel yoke and determine the length of the magnet. The main flux direction in the gap is horizontal and perpendicular to the magnel length axis.

\section{MAGNET CORI?.}

The slicel yoke of the magnet has to provide a llux return path for the magnetic fied in the fiducial volume. The dimensions of the core patts have been chosen lor specified steel characteristics in order to minimize the lakage flux. During operation at nominal field the level of flux density in the sted parts will be close to the saturation value. The absence of constraints on the field quality resulted in a design focused on low matcrial and manufacturing cost. The relurn yoke has, consequently, been designed as window frame type with hotizontal boltom and lop beams 
of trapezoidal shape. The poles are formed by the vertical rectangular side walls.

The proposed construction is lyased on existing steel stacks, which are available from a fortner magnet project that has been abandoned. The iron yoke is made of modules of about $45 \mathrm{~cm}$ thickness. Each module consists of $3 \mathrm{~cm}$ thick plates joined under pressure and welded through previously machined holes.

The modules will have to be cul to the required dimensions. The top and bottom parts will be assembled from seven modules cach. The sidewalls are otiented in an angle of 9 degree with respect to the length axis of the magnet and colssist of seven modules cach.

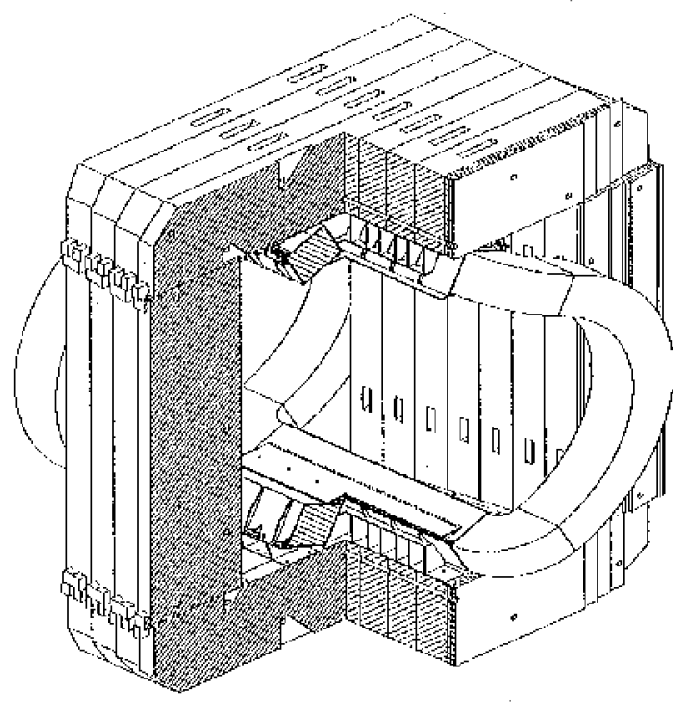

Figure 1 Dipole Magnet assembly

\section{EXCITATION WINDINGS}

\section{A. Description of the coil parameters}

The excitation windings consist of two nnirror symmetrical sacldle-shape coils. A coil is constructed from 12 pancakes with 12 turns each. The cross-section of the winding is rectangular. The longitudinal parts of the coil are parallel to each other. The coil ends have a half-cylindrical shape. The bends of the coil lie in one plane and transit smoothly into the cylindrical part of the coil ends. The coils will be wound from hollow conductor extruded from $99.5 \%$ purity aluminum.

The thermal expansion of the coil will be of the order of 4 to $5 \mathrm{~mm}$ during magnet operation. Therefore, the coil will slightly move along the longitudinal supports. The saddlc parts of the coil will be clamped to the polc ends with the help of ribs and intermediate rubber sheets.

The electrical connections will be located on the outer perimeter of the coil ends. The connection between adjacent layers will consist of welded plain Aluminum bars of large cross-section.
The water inless will be connected to the water collector's via manifolds and rubber pipes.

\section{B. Coil manufacturing methods}

\section{1) Continuous winding concept.}

The conductor ean be cxtruded, as a single cul for the length needed to wind one coil layer. Internal welds in the coils en consequently be avoided.

A heat treatment at 150 degrec $C$ is considered to be sufficient to relieve strain and stresses in the conductor which appear during the winding process.

The steps of the coil manulacturing process are described in the following.

\section{Flat pancake}

Each coil layer, corresponding to a cooling circuit, is wound flat on a mandrel. The facility for winding the tlat layer includes the winding machine, the payolf, the device for aligning, the tension device, the cleaning unit, the taping unit, and the dovice for passing the conductor. The winding procedure is cartied out with constant tension to maintain the mechanical propertics and homogeneily while bending the sections. The conductor will be aligned and straightened simultancously by applying some tension. The insulation is applied before the bending of the concluctor during the winding process. The jig for winding the flat racetrack coil is placed on the turntable of the winding machine.

2. Saddle shaping

In the semi-cylindrical parts of the winding, the bending radius of each layer is greater than $2 \mathrm{~m}$ and leads to a very small deformation ( $1.25 \%)$ of the conductor cross-section. Consequently, the previously wrapped conductor insulation should not be degraded when bending one coil layer to the 3-dimensional shape.

Bending the flat layer is carticd out on a cylindricat fixture, see Fig. 2. Nfter the bending process, the dimenstons of the external perimeter of the layer are corrected with clamps. During the shaping process of a layer, the cylindtical surface of the fixture will be the reference for the inner cylindrical surfaces of each layer. Massive clamps along the straight parts of the coils will be used to bend the linyer to the cosired goometry immediately after the winding. Halfcylindrical phates will confine the layers alter bending.

3. Coil assembly

The pancakes are stacked with pre-preg interlayer insulation. It is assumed that $1 \mathrm{~mm}$ thickness wili be sufficient for compensating the inaccuracy of the layer 
manufacturing. The coil dimensions will be referenced to the innemost cylindrical surface and to the inner perimeter of the complete pancake stack.

All layers ol one coil are kept under compression to control the outside dimensions during polymerization at 160 degree $C$.

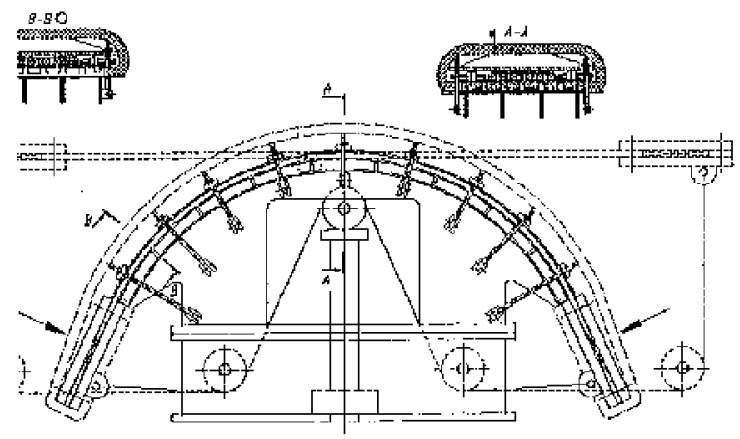

Figure 2 Coil shaping concept

\section{2) Weided construction}

This construction method relies on a good control of the welding process for aluminum proliles. It is believed that this can be obtained with orbital welding machines. In a previous version for excitation coils with a conical shape, which followed closely the required aperture, this method has been introduced and deseribed in detail 141. For the present cylindrical geometry of the coils the manufacturing process can be lurther simplified.

$\Lambda$ latf turn is formed from a straight Aluminum bar of adequate length. This requires unit lengths of approximately $12 \mathrm{~m}, \Lambda$ single bending angle of 90 degrees is sufficiont to form the coil pancakes.

Fout bending operations are necessary per halî turn to bond the conductor at each coil end upwards, i.e ont of the coil plane, and then inwards, i.c. towards the length axis of the coil.

The construction from half turn modules results not only in shorter conductor length to be handled but also reduces the tooling sel drastically. Since the conductor has a square cross-section the bending radii required for the inward bends are included in those necessaty for the upward bends. Therefore, only 12 tools are required lor all bends. The described bending procedure allows in principle to exceule all bending operations horizontally. For the inward bends this requites, however, to turn the work piece in the vertical ditection.

\section{Bending sequence}

(a) The straight conductor bar has been cut to lenglh of one balf turn, cleaned and degreased (b) The "Upward" bends can now be exceuted, either" by displacing the tool to the opposite side alier the 1 st bend or by turning the work piece by 180 degrees.

(c) To execute the "Inward" bends it will bo necessary to either turn the work piece in the vertical direction and perform horizontal bending operations or to make vertical 90 degr'ee bends.

It is obvious from the number of radii with jespect to the number of bends that an important rationalization can be ohtained by producing identical bends in series on difrerent work pieces. This will reduce the nimber of tool fitting operations to at most twice the number of tadii, $i, e, 24$.

\section{Pancake Assembly}

Each tum will be assembled by welding of two hall turos as shown in Fig. 3. 264 internal welds will, therefore, be necessary to build one coil. In addilion 22 welds are required for the water and electrical terminal connections. Fach balf turn in a pancake has a different total Iength to obtain the necessary cliange in pitch by one conkluctor width.

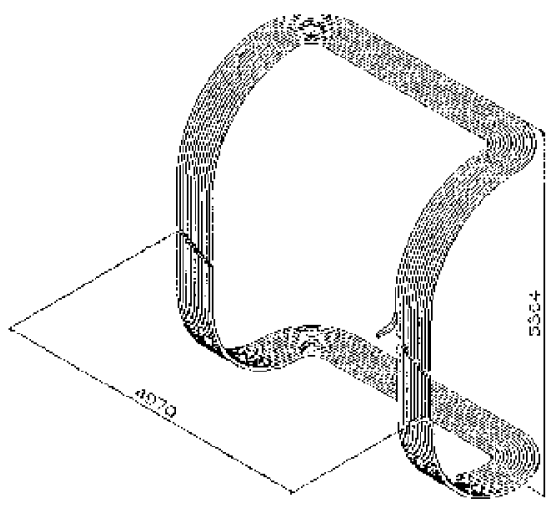

Figure 3 Pancake assembly

It ordet to provide sufficient clearance for the welding operation the last turn will be spread apart from the previous lurns by an adequate tool. Bending tools must be dimensioned to obtain the space between turns which is necessary for the insulation materal. It might therefore be considered to apply the conductor insulation immediately after the assembly of a turn in order to control the dimensions continuously.

3. Insulation Method

The conductor insulation can be wrapped after completion of each turn or alter assembly of a complete pancake. The bending ralii are chosen large enough to allow the use of an atlotnatic wrapping machine. The clearance between turns necded for the passage of the machine can be casily obtained will? adequate jigs. The insulated pancake will then form a 
gcometrically woll defined strueturc itıside given tolerances.

Depending on the insulation material used, different steps have to be envisaged. In case of classic vacuum impregnation, the introduction of the epoxy resin will follow after the assembly of a complete coil insicle a Inould. 'This procedutc is, howevel', technically rather" complex due to the 3 dimensiomal shape of the coils. Pumping of the resin over mote than two meter height would be required.

The use of an insulation method with pre-impregnaled glass tiber wrapping scems, therefore, to be mote attractive. The coil fabrication method is clearly suited for this procedure since the complete winding can be assembled prior to insulation.

4. Coil Assembly

The assembly of a coil is a straightforward operation. It regutres the stacking of the previously assembled and insulated pancakes. Once the turns have been wound and welded to form the number of pancakes required for a coil, the conductor and coil insulation wan be applied even within shot time margins requited by the potting time for the pre-preg insulation material.

The stacking follows the Russian doll procedure with the innormost pancake well supported in a stacking lixture and the coil ends facing downwards. The orientation is proposed to avoid mechanical stress during the assembly when the coil ends are not supported. In addition, the assembly fixturc can also be used as handling and transportation jig.

\section{Coil Insulation}

Different methods can be envisaged to apply and cure the themosetting resin once the ground insulation has been wrapped. In principle the building of a vacuutn tight cover around the coil should not raise technical problems. However, the coil dimensions need to be controlled by a reasonably precise mould. The curing of the resin could be envisaged by circulaling hot demineralized water in the conductor cooling ducts.

\section{Power dissipation and cooling requirenents}

The direct water cooling of the conductors will remove the major part of the generated heat in the excitation windings. The residual dissipated heat will be intereepted by water cooled heat exchangers in fortn of aluminum shields, which will be installed to protect the detector chambers in the magnet.

Adelitional cooling will be provided for the busbar system between the power converter, which will be located above ground at a distance of about $110 \mathrm{~m}$ from lite dipole matgnet.

\section{MAGNE'T ASSEMBLY}

Several successive assemblies of the magnet are planned. The construction concept takes this into account. Once the first assembly of the yoke has been successfully terminated, subseguent re-asscmblics will not require realignment of the sub-units. The machined faces at the extemal sicles of the horizontal parts which are used as references lor the mating faces between horizontal beams and uprights will also serve as support areas for the moving base.

Consequently, an alignment of the base should be sufticient for the position of the magnet.

Tension rods will be used to consolidate the horizontal beams and the uptights. Adequatcly positioned dowel pins will guarantec the aligmment between sub-units. The mechanical assembly of horizontal and vertical yoke parts has to take the geometry of the yoke into account. To glarantce a precise match at the junction between these items, flanges will be welded at the extremities of the subunits and machined simultaneously with the mating surfaces. The mechanical connection will then be achieved wilh tension bolts between flanges.

\section{CONCLUSIONS}

Both manufacturing methods are considered to be feasible. The winding of continuous pancakes looks attractive since interual welds can be avoided. At the present state this method requires still a considerable amount of validation and testing but it is hoped to gain a reduction in cost with respect to the welkled coils. In comparison to the welded construction it can, however, be noliced that a sulsstantially heavier and more complex tooling will be reguired. The wrapping of the conductor insulation before winding will allow to use existing equipment but might require repair alter bending.

The welded construction Incthod has already successfully been applied. It should be emphasized that an irreproachable quality can be obtained with state of the art welding equipment. In addition, contrary to the previous method, repair of laulty sections will be possible during all stages of the coil construction without important material loss. In addition, dimensional tolerances can be controlled and corrected during the assembly of each turu.

\section{Reterentes}

[1] PDR tor the Dipole Maglel of the Muon Spectrometer, ALICligg-07 - Alice Dipole Magna Project WG, JINR/CERN

[2] ALICE Muon Arm Dipole Magnet Conceptunl Design Report. ALICE99-06, D. Swobodi, CERN

[3] TIR for the Dismen l'or ward Spectroneter, CFRN/LHCC 99-22, ALICE TDR 5, 13 Aug. 1909

[4] A Coil manufacturing procedure for the ALICE Muon Arm Dipole Magnut, ALICE/98-32, TST T-LIBA98-02, D. Swoboda, CERN 